\title{
IMPLEMENTASI K-MEANS CLUSTERING PADA PENGELOMPOKAN POTENSI KERJASAMA PELANGGAN
}

\author{
Ragil Prasojo ${ }^{1)}$; Yustina Retno Wahyu Utami ${ }^{2}$; Retno Tri Vulandari ${ }^{3)}$ \\ 1)2)3) Program Studi Teknik Informatika STMIK Sinar Nusantara \\ Email : ${ }^{1)}$ ragilsinus@gmail.com; ${ }^{2)}$ yustina_retno@sinus.ac.id; ${ }^{3)}$ retnotv@sinus.ac.id
}

\begin{abstract}
Tight competition in the business world today, the number of MSMEs engaged in the same field, this requires MSMEs to develop strategies to achieve goals. Apart from having to develop products and services, an MSME must also retain customers. Therefore grouping of potential customers is needed. By utilizing data that is an indicator of the customer. This utilization is called data mining. Data mining is run based on data that has been determined that is customer data, number of accessories, cooperation time, and item returns. Therefore in this study a potential customer collaboration system was designed using the K-Means method, so that potential customers are obtained. The results of this study are a web-based system application that can classify customers with the K-Means method. Grouping into 3 clusters, the first cluster with enough criteria consists of 7 customer data. This criterion consists of customers who have a small amount of goods purchased and a large number of goods returned. The second cluster consists of 17 customer data with good criteria. This criterion consists of customers who have a large number of goods purchases and few goods returns. The third cluster consists of 7 customer data with very good criteria. This criterion consists of customers who have the most number of purchases and the least return of goods.
\end{abstract}

Keywords : Customer, Data Mining, K-Means Clustering

\section{PENDAHULUAN}

Persaingan yang ketat di dunia usaha saat ini mengharuskan perusahaan benarbenar menyusun strategi untuk mencegah terjadinya perpindahan pelanggan. Maka dari itu tujuan dari penelitian ini adalah mengelompokan pelanggan yang berpotensi untuk menjadi pelanggan tetap atau pelanggan potensial, sehingga perusahaan dapat mempertahankan pelanggan potensial tersebut dengan cara memberikan pelayanan prima, reward, ataupun sebagai target utama dalam promosi produk baru. Pengelompokan pelanggan ini dapat dilakukan dengan melihat tingkat loyalitas pelanggan. Tingkat loyalitas pelanggan dapat diukur dengan menggunakan pengelompokan dari jumlah transaksi dan total pembelian. Dengan menggunakan data jumlah transaksi dan total pembelian dari setiap pelanggan bisa dilakukan penambangan data (data mining) menggunakan metode K-Means Clustering.

K-Means adalah metode pengelompokan data dengan mengambil parameter sejumlah cluster, dan mempartisi data kedalam cluster tersebut, dengan berpatokan pada kemiripan antar data dalam satu cluster dan ketidakmiripan di antar cluster yang berbeda, pusat dari cluster adalah rata-rata dari nilai anggota cluster yang disebut centroid. Selain itu algoritma K-Means Clustering dinilai memiliki teknik yang sangat cepat dalam proses clustering untuk pengelompokan pelanggan potensial [1].

\section{TINJAUAN PUSTAKA}

\subsection{Penelitian Terkait}

Berikut empat jurnal penelitian terdahulu yang terkait dengan pengelompokkan data mengunakan metode K-Means Clustering :

1. Penelitian yang dilakukan oleh Hartatik, mengenai Pengelompokkan Mahasiswa Berdasarkan Nilai Ujian Nasional dan Ipk Menggunakan Metode K-means. Dalam penelitian ini penulis menggunakan 2 keriteria yaitu nilai Tes Seleksi dan nilai UN yang berfungsi sebagai parameter. Dalam penentuan jumlah cluster, penulis menentukannya menjadi 3 Cluster. Kemudian data nilai 2 kriteria tersebut dimasukkan kedalam sistem dan dilakukan proses K-Means, kemudian di temukan hasil akhir berupa pola pengelompokkan mahasiswa yang menunjukkan bahwa mahasiswa yang masuk dengan nilai UN tidak selamanya memiliki IPK terbaik [2]. 
2. Penelitian yang dilakukan oleh Nasari \& Darma, dalam studi Penerapan K-Means Clustering Pada Data Penerimaan Mahasiswa Baru. Dalam penelitian ini data yang akan diolah berjumlah 278 data. Penulis menggunakan 3 kriteria antara lain nilai UAN, asal sekolah dan prodi. Cluster yang ditentukan berjumlah 2 cluster. Setelah dilakukan perhitungan K-Means, disimpulkan bahwa siswa yang berasal dari sekolah SMA rata-rata memilih jurusan Sistem Informatika dan siswa yang berasal dari sekolah SMK rata-rata memilih jurusan Teknik Informatika [3].

3. Penelitian dilakukan oleh Candra Purnamaningsih dengan Judul Pemanfaatan Metode K-Means Clustering dalam Penentuan Penjurusan Siswa SMA. Penelitian ini dibangun suatu sistem untuk mengelompokkan data yang ada berdasarkan dari nilai akademik, nilai IQ, dan minat siswa tersebut untuk penjurusan siswa SMA untuk jurusan IPA dan IPS. Pengelompokkan data dilakukan dengan menggunakan metode clustering K-Means yaitu dengan mengelompokkan $n$ buah objek ke dalam $k$ kelas berdasarkan jaraknya dengan pusat kelas. Dari hasil penelitian, dapat disimpulkan bahwa algoritma klasifikasi K-Means dapat digunakan untuk penjurusan siswa SMA dengan akurasi 0,9005882 untuk jurusan IPA dan IPS berdasarkan nilai akademik, nilai IQ, dan minat siswa [4].

4. Penelitian yang dilakukan oleh Istiqomah Sumadikarta, Evan Abeiza dengan judul Penelitian Penerapan Algoritma K-Means Pada Data Mining Untuk Memilih Produk Dan Pelanggan Potensial. Penelitian pada perusahaan mengalami permasalahan kesulitan dalam memasarkan produk dan mempertahankan pelanggan. Berdasarkan permasalahan tersebut penelitian ini untuk mengetahui pelanggan yang berpotensial atau tidak dan produk yang akan ditambah atau dikurangi. Penelitian ini menggunakan metode alogaritma K-means clustering untuk mengelompokkan data pelanggan dan data produk yang perlu dipertahankan atau tidak [5].

\subsection{K-Means Clustering}

K-Means adalah salah satu algoritma clustering yang sangat popular karena kesederhanaan dan kemampuannya dalam menangani data dengan skala besar. Namun demikian algoritma ini sangat sensitif terhadap centroid awal. Perbedaan centroid awal akan memberikan perbedaan hasil clustering dan apabila centroid awal yang diberikan adalah centroid yang tidak baik maka dapat dipastikan hasil clusteringnya juga tidak baik.[6]

K-means memiliki beberapa keuntungan yang berbeda dibandingkan dengan algoritma pengelompokan lainnya. Artinya, K-means merupakan algoritma yang sangat sederhana dan kuat, sangat efisien, dan dapat digunakan untuk berbagai macam jenis data. Selain itu, K-means memiliki kelemahan mengenai optimasi, misalnya masalah generalisasi jarak centroid. Muncul dalam data dengan sifat yang rumit, seperti skala besar, tinggi dimensi, kelas tidak seimbangan, dan juga perlu beradaptasi untuk skenario data yang berbeda. Beberapa kerugian dari K-means, seperti berkinerja buruk untuk non-globular clusters, dan menjadi sensitif terhadap outlier[6].

Dengan metode pengelompokan berdasarkan jarak, teknik K-means yang dianggap sebagai metode pengelompokan klasik. Salah satu fitur utama yang membuat K-means berguna dalam penelitian ini adalah kemungkinan menentukan terlebih dahulu berapa banyak cluster yang sedang dicari. Jumlah ini mengacu pada parameter K. Dari jumlah ini, poin $\mathrm{K}$ dipilih dalam cluster random sebagai pusat cluster. Semua variabel ditugaskan ke pusat cluster terdekat mereka sesuai dengan metrik jarak Euclidean. Dengan rumus jarak Euclidean Distance sebagai berikut :

$$
\begin{aligned}
& \left.d(x, y)=|x-y|=\sqrt{\sum_{i=1}^{n}\left(x_{i}-y_{i}\right.}\right)^{2} \\
& \text { Dimana : } \\
& \mathbf{d}=\text { Jarak ( Euclidean Distance ) } \\
& \mathbf{x}=\text { data } \\
& \mathbf{y}=\text { centroid }
\end{aligned}
$$

Langkah selanjutnya adalah menghitung centroid dari mean dari contoh di setiap cluster. Kemudian centroid ini diambil untuk menjadi nilai-nilai pusat baru. Hasil algoritma K-means diterapkan pada set data. K-means merupakan teknik sederhana dan efektif, 
memberikan hasil yang diverifikasi dan berguna [6].

Kelemahan K-means clustering tersebut dapat diatasi dengan menggunakan metode yang tepat pada saat menentukan centroid awal. Untuk menentukan ketepatan metode pada kasus penentuan potensi kerjasama pelanggan, maka digunakan dua metode penentuan centroid awal yang berbeda. Kedua metode tersebut adalah simple random sampling dan analogy based estimation[6].

Parameter yang digunakan dalam penelitian ini adalah jumlah iterasi dalam proses perhitungan K-means terpendek dan memiliki anggota tetap atau perbedaan jarak antar centroid dengan iterasi sebelumnya. Untuk menghitung centroid cluster ke-i, $\mathrm{V}_{\mathrm{i}}$, digunakan rumus sebagai berikut :

$$
v_{i k}=\frac{\sum_{k=1}^{N_{1}} x_{i k}}{N_{i}}
$$

Nilai centroid baru $\left(\mathrm{V}_{\mathrm{ik}}\right)$ adalah jumlah data pada cluster ke-i dibagi jumlah data yang menjadi anggota cluster ke-i $\left(\mathrm{N}_{\mathrm{i}}\right)$. Sebagai contoh pada penentuaan centroid baru cluster 1 pada iterasi pertama. [6]

Dalam perhitungan K-Means jika ada data dengan perbedaan besaran angka yang cukup jauh maka data perlu dinormalkan. Normalisasi data bisa dilakukan dengan menggunakan rumus:

$$
\text { Nilai Normalisasi }=\frac{\text { Nilai Data } \text { Aktual }}{\text { Nilai } \text { DataMaksimum }}
$$

Normalisasi data input bertujuan untuk menyesuaikan nilai range data agar berada pada range 0 sampai 1 [7].

\section{METODE PENELITIAN}

Perancangan sistem pengelompokan pelanggan potensial dilakukan dengan metode Waterfall dan metode pengumpulan data serta perancangan sistem.

\subsection{Metode Pengumpulan Data}

Tahap ini digunakan untuk mendapat informasi yang tepat dan akurat penulis berusaha menggunakan metode pengumpulan data yang sesuai dengan pokok permasalahan yang akan diteliti. Data diperoleh dari jenis data kualitatif dan kuantitatif. Sumber data berasal dari data primer dan data sekunder yang diperoleh dengan cara observasi, wawancara, dan pencatataan secara sistematis.

\subsection{Metode Perancangan Sistem}

Pada tahap ini dibutuhkan metode yang dapat mendefinisikan data secara jelas. Tahapan-tahapan yang dilakukan untuk membuat aplikasi sebagai berikut.

1. Tahap analisis sistem

Tahap ini dilakukan analisa kebutuhan sistem yang meliputi komponen hardware, software dan bahan penelitian. Tahap ini bertujuan untuk memenuhi kebutuhan dalam pengembangan sistem serta kebutuhan lain dalam pembuatan basis data.

2. Tahap desain sistem

Tahap ini dibuat sebelum tahap pengkodean. Tujuan dari tahap ini adalah memberikan gambaran tentang apa yang akan dikerjakan dan bagaimana bentuk tampilannya. Tahap ini memenuhi semua kebutuhan pengguna sesuai dengan hasil yang dianalisa yaitu rancangan sistem pengelompokan pelanggan potensial dan membantu mendefinisikan arsitektur sistem secara keseluruhan. Dokumentasi yang dihasilkan dari tahap desain sistem ini antara lain perancangan Diagram Konteks, Hierarchy Input Process Output (HIPO), Data Flow Diagram (DFD), Kamus Data, Entity Relationship Diagram (ERD), Flow Chart, dan Desain Tabel Basis Data.

\section{Tahap implementasi sistem}

Implementasi sistem ini menerapkan perancangan sistem ke dalam sistem berbasis web dengan menggunakan PHP sebagai bahasa pemograman dan MySQL sebagai database.

4. Tahap pengujian sistem

Ada dua tahap pengujian yaitu pengujian fungsionalitas dan validasi. Pengujian fungsionalitas sistem dengan blackbox untuk mengetahui bila terjadi kesalahan atau kekurangan sehingga sistem yang dibuat dapat diperbaiki untuk menghasilkan sistem sesuai yang diharapkan. Pengujian validasi dengan cara membandingan sistem yang telah dibangun dengan $K$-means dibandingkan dengan aplikasi Microsoft excel untuk mengetahui tingkat akurasi aplikasi yang dibuat [8].

\section{HASIL DAN PEMBAHASAN}

\subsection{Perhitungan K-Means}

Metode K-Means Clustering digunakan untuk mengelompokan suatu data dengan menentukan cluster yang nantinya akan di gunakan untuk sistem pengelompokan pelanggan potensial. Ada 31 data pelanggan yang dihitung dengan $K$-Means sesuai dengan 
kriteria masing-masing. Ke-31 data pelanggan ditunjukkan pada Tabel 1.

Tabel 1. Data Pelanggan

\begin{tabular}{|l|c|c|c|c|}
\hline $\begin{array}{c}\text { Pelangga } \\
\mathrm{n}\end{array}$ & $\begin{array}{c}\text { Iml. } \\
\text { Akseso } \\
\text { ris }\end{array}$ & $\begin{array}{c}\text { Lama } \\
\text { Kerjasama } \\
\text { (Tahun) }\end{array}$ & Return & $\begin{array}{c}\text { Jenis } \\
\text { Aksesoris }\end{array}$ \\
\hline P1 & 80 & 1 & 2 & Audio \\
\hline P2 & 70 & 2 & 4 & Audio \\
\hline P3 & 50 & 1 & 3 & Audio \\
\hline P4 & 90 & 4 & 6 & Gaming \\
\hline P5 & 90 & 3 & 4 & Gaming \\
\hline P6 & 40 & 2 & 0 & Gaming \\
\hline P7 & 80 & 2 & 3 & Audio \\
\hline P8 & 60 & 3 & 2 & Storage \\
\hline P9 & 50 & 2 & 4 & Storage \\
\hline P10 & 50 & 1 & 3 & Networki \\
\hline P11 & 70 & 3 & 6 & Audio \\
\hline P12 & 70 & 2 & 2 & Audio \\
\hline P13 & 50 & 2 & 0 & Gaming \\
\hline P14 & 80 & 1 & 2 & Gaming \\
\hline P15 & 80 & 4 & 4 & Storage \\
\hline P16 & 40 & 1 & 0 & Audio \\
\hline P17 & 50 & 2 & 3 & Gaming \\
\hline P18 & 80 & 3 & 4 & Gaming \\
\hline P19 & 80 & 2 & 3 & Audio \\
\hline P20 & 90 & 1 & 2 & Audio \\
\hline P21 & 90 & 4 & 4 & Audio \\
\hline P22 & 70 & 2 & 0 & Gaming \\
\hline P23 & 80 & 3 & 2 & Storage \\
\hline P24 & 50 & 2 & 0 & Networki \\
\hline P25 & 50 & 2 & 2 & Gaming \\
\hline P26 & 40 & 3 & 0 & Audio \\
\hline P27 & 60 & 1 & 5 & Gaming \\
\hline P28 & 50 & 2 & 2 & Audio \\
\hline
\end{tabular}

Dari data pada Tabel 1 maka data harus kita normalkan dengan cara mencari skala per kriteria dari kriteria jumlah aksesoris, lama kerjasama, dan return.

Untuk penormalan data menggunakan rumus persamaan (3). Hasil per normalan data
$\mathrm{JA}=80: 90$
$=0.88888889$
$\mathrm{LK}=1: 4$
$=0.25$
$\mathrm{R}=2: 6$
$=0.33333333$

Tabel 2. Hasil Penormalan Data

\begin{tabular}{|c|c|c|c|}
\hline Pelanggan & $\begin{array}{c}\text { Jumlah } \\
\text { Aksesoris }\end{array}$ & $\begin{array}{l}\text { Lama } \\
\text { Kerjasama } \\
\text { ( Tahun) }\end{array}$ & Return \\
\hline P1 & 0.888888889 & 0.25 & 0.333333333 \\
\hline P2 & 0.777777778 & 0.5 & 0.666666667 \\
\hline P3 & 0.555555556 & 0.25 & 0.5 \\
\hline P4 & 1 & 1 & 1 \\
\hline P5 & 1 & 0.75 & 0.6666666667 \\
\hline P6 & 0.444444444 & 0.5 & 0 \\
\hline P7 & 0.888888889 & 0.5 & 0.5 \\
\hline P8 & 0.666666667 & 0.75 & 0.333333333 \\
\hline P9 & 0.555555556 & 0.5 & 0.666666667 \\
\hline P10 & 0.555555556 & 0.25 & 0.5 \\
\hline P11 & 0.777777778 & 0.75 & 1 \\
\hline P12 & 0.777777778 & 0.5 & 0.333333333 \\
\hline P13 & 0.555555556 & 0.5 & 0 \\
\hline P14 & 0.888888889 & 0.25 & 0.333333333 \\
\hline P15 & 0.888888889 & 1 & 0.666666667 \\
\hline P16 & 0.444444444 & 0.25 & 0 \\
\hline P17 & 0.555555556 & 0.5 & 0.5 \\
\hline P18 & 0.888888889 & 0.75 & 0.666666667 \\
\hline P19 & 0.888888889 & 0.5 & 0.5 \\
\hline P20 & 1 & 0.25 & 0.333333333 \\
\hline P21 & 1 & 1 & 0.666666667 \\
\hline P22 & 0.777777778 & 0.5 & 0 \\
\hline P23 & 0.888888889 & 0.75 & 0.333333333 \\
\hline P24 & 0.555555556 & 0.5 & 0 \\
\hline P25 & 0.555555556 & 0.5 & 0.333333333 \\
\hline P26 & 0.444444444 & 0.75 & 0 \\
\hline P27 & 0.666666667 & 0.25 & 0.833333333 \\
\hline P28 & 0.555555556 & 0.5 & 0.333333333 \\
\hline P29 & 0.888888889 & 0.75 & 0.833333333 \\
\hline P30 & 0.888888889 & 0.5 & 0.6666666667 \\
\hline P31 & 0.822222222 & 0.75 & 0.166666667 \\
\hline
\end{tabular}

Kemudian tentukan banyak cluster yang akan dibentuk. Pada penelitian ini terdapat tiga cluster yaitu Cluster 1 disebut dengan C1, Cluster 2 disebut dengan C2, dan Cluster 3 disebut dengan C3.

Kemudian tahap kedua yaitu menentukan pusat cluster, dengan cara memilih data pelanggan di Tabel 2 yang memiliki nilai tertinggi, nilai medium dan nilai terendah. Untuk cluster awal $\mathrm{C} 1$ didapat dari data nilai di kolom jumlah aksesoris. Cluster awal C2 didapatkan dari data nilai di kolom lama 
kerjasama. Sedangkan untuk C3 didapatkan dari data nilai di kolom return. Setelah pengambilan data sesuai dengan cara diatas, maka diperoleh nilai pusat awal cluster untuk Cluster 1, Cluster 2, dan Cluster 3 sebagai berikut :

$$
\begin{aligned}
& \mathrm{C} 1=(1,0.7777778,0.44444444) \\
& \text { C2 }=(1,0.5,0.25) \\
& \text { C3 }=(1,0.5,0)
\end{aligned}
$$

Berdasarkan persamaan (1) jarak pusat cluster pertama diperoleh :

$d_{1}=\sqrt{(0.8888889-1)^{2}+(0.25-0.777778)^{2}+(0.3333333-0.44444)^{2}}=0.550673$

$d_{2}=\sqrt{(0.8888889-1)^{2}+(0.25-0.5)^{2}+(0.3333333-0.25)^{2}}=0.28598972$

Jarak pusat cluster ketiga

$d_{3}=\sqrt{(0.8888889-1)^{2}+(0.25-0.5)^{2}+(0.3333333-0)^{2}}=0.431227075$

Dari hasil perhitungan di atas maka dihasilkan nilai cluster 1 yaitu 0.550672988 cluster 2 yaitu 0.0285989726 dan cluster ke 3 yaitu 0.431227075 . Hasil perhitungan di atas

\begin{tabular}{|c|c|c|c|c|c|}
\hline No & Nama & $\mathrm{Cl}$ & $\mathrm{C}_{2}$ & C3 & $\begin{array}{c}\text { Jarak } \\
\text { Terpendek }\end{array}$ \\
\hline 1 & P1 & C.55067.2988 & 0.285989726 & 0.431227075 & 0.285989726 \\
\hline 2 & P2 & C.419<3.5249 & 0.4722222222 & 0.702728369 & $0.419<35249$ \\
\hline 3 & P3 & C.692218655 & 0.567918008 & $0.714164<52$ & 0.567918008 \\
\hline 1 & P4 & C. 598351649 & 0.901387819 & 1.113033989 & 0.598351649 \\
\hline 2 & $\mathrm{~Pb}$ & $C .223951609$ & 0.485912658 & 0.712000512 & 0.223951609 \\
\hline 6 & 56 & C.76376.2614 & 0.609214228 & 0.555555556 & 0.555555556 \\
\hline 7 & P7 & C.304290311 & 0.273579383 & 0.512196914 & 0.2735793 .83 \\
\hline 8 & P8 & C. $352<60486$ & 0.424918292 & 0.533593686 & 0.352460486 \\
\hline 9 & P9 & C.56927.5044 & 0.609214228 & 0.801233617 & 0.569275044 \\
\hline 10 & P10 & $c .6922$ & 0.567918008 & $0.714164<52$ & 0.567918008 \\
\hline 11 & P11 & C.59899.6078 & 0.821208083 & $1.054458-94$ & 0.598996078 \\
\hline 12 & P12 & C.372677995 & 0.237333437 & 0.405616808 & 0.237333437 \\
\hline 13 & P13 & C.687184268 & 0.509932215 & $0.444444<44$ & $0.444 \angle 44444$ \\
\hline 14 & $\mathrm{P} 14$ & C. .5506 & 0.2859 & 0.431227075 & 0.285989726 \\
\hline 15 & P15 & C. 333 & 0.66027024 & 0.840708109 & 0.333333336 \\
\hline 16 & P16 & C.8 & 0.65 & 0.60 & 0. \\
\hline 17 & P17 & (..52. & 0.5099 & 0.663 & 0.509 \\
\hline 18 & P18 & C. 250000004 & 0.498454402 & 0.725617876 & 0.250000004 \\
\hline 19 & P19 & C.304290311 & 0.273579383 & 0.512196914 & 0.273579383 \\
\hline 20 & P20 & C.539346884 & 0.263523138 & 0.415666666 & 0.263523138 \\
\hline 21 & P21 & $C .3142$ & 0.65085414 & 0.833 & 0.314269684 \\
\hline 22 & P22 & 6.5692 & 0.334488738 & 0.222222222 & 0.2222222222 \\
\hline 23 & P23 & C. 159571182 & 0.285989726 & $0.43 \llbracket 227075$ & 0.159571182 \\
\hline 24 & P24 & $C .687184268$ & 0.509932215 & $0.444444<44$ & $0.444 \angle 44444$ \\
\hline$\frac{25}{25}$ & P25 & C. 53575.8375 & 0.452189461 & 0.555555555 & 0.452189461 \\
\hline 26 & $\mathrm{P} 26$ & 0.71200031 & 0.658514978 & 0.609214228 & 0.609214228 \\
\hline 27 & P27 & $C .735<5.5685$ & 0.716860438 & 0.93169499 & 0.716860438 \\
\hline 28 & P28 & C.5357583775 & 0.452189461 & 0.555555555 & 0.452189461 \\
\hline 29 & P2O & C. $405<0.3324$ & 0.64430075 & 0.877091855 & $0.405<03324$ \\
\hline 30 & $\mathrm{P} 30$ & C.372677999 & 0.431227075 & 0.675862504 & 0.372677999 \\
\hline 31 & P31 & C.33096.3796 & 0.317882656 & 0.349117052 & 0.3178826 \\
\hline
\end{tabular}
ditunjukkan pada Tabel 3.

\section{Tabel 3. Hasil perhitungan iterasi ke 1}

Setelah mendapatkan hasil dari perhitungan iterasi pertama pada Tabel 3 . Hitung kembali titik pusat (centroid) pada masing-masing cluster dengan menggunakan rumus persamaan (2). Berikut perhitungan untuk menentukan pusat cluster dari Tabel 3.
Cluster pertama ada 12 data :

$\mathrm{C} 1=\frac{\text { Jumlah nilai kriteria } 1 \text { cluster } 1}{\text { Jumlah data anggota cluster } 1}=\frac{10.2222222}{12}=0.851851852$

$\mathrm{C} 1=\frac{\text { Jumlah nilai kriteria } 2 \text { cluster } 1}{\text { Jumlah data anggota cluster } 1}=\frac{9}{12}=0.75$

$\mathrm{C} 1=\frac{\text { Jumlah nilai kriteria } 3 \text { cluster } 1}{\text { Jumlah data anggota cluster } 1}=\frac{8.16666668}{12}=0.680555555$

Cluster kedua ada 13 data :

$\mathrm{C} 2=\frac{\text { Jumlah nilai kriteria } 1 \text { cluster } 2}{\text { Jumlah data anggota cluster } 2}=\frac{9.6000003}{13}=0.73846153$

$\mathrm{C} 2=\frac{\text { Jumlah nilai kriteria } 2 \text { cluster } 2}{\text { Jumlah data anggota cluster } 2}=\frac{5.25}{13}=0.40384615$

$\mathrm{C} 2=\frac{\text { Jumlah nilai kriteria } 3 \text { cluster } 2}{\text { Jumlah data anggota cluster } 2}=\frac{5.49999998}{13}=0.42307692$

Cluster ketiga ada 6 data :

C3 $=\frac{\text { Jumlah nilai kriteria } 1 \text { cluster } 3}{\text { Jumlah data anggota cluster } 3}=\frac{3.2222222222}{6}=0.537037037$

C3 $=\frac{\text { Jumlah nilai kriteria } 2 \text { cluster } 3}{\text { Jumlah data anggota cluster } 3}=\frac{3}{6}=0.5$

C3 $=\frac{\text { Jumlah nilai kriteria } 3 \text { cluster } 3}{\text { Jumlah data anggota cluster } 3}=\frac{0}{6}=0$

Setelah pusat cluster (centroid) ke 2 di tentukan, ulangi perhitungan untuk menentukan nilai cluster pada tiap data untuk menghasilkan nilai pada Iterasi ke 2. Iterasi ke 2 ditunjukan pada Tabel 4.

Tabel 4. Hasil perhitungan iterasi ke 2

\begin{tabular}{|l|c|c|c|c|}
\hline Nama & C1 & C2 & C3 & Jarak Terpendek \\
\hline P1 & 0.609864751 & 0.233132878 & 0.545353864 & 0.233132878 \\
\hline P2 & 0.261112753 & 0.264815582 & 0.708802193 & 0.261112753 \\
\hline P3 & 0.608598228 & 0.251078469 & 0.559323641 & 0.251078469 \\
\hline P4 & 0.431847921 & 0.869851718 & 1.210096982 & 0.431847921 \\
\hline P5 & 0.148797765 & 0.497554837 & 0.849281549 & 0.148797765 \\
\hline P6 & 0.831646957 & 0.524104662 & 0.092592593 & 0.092592593 \\
\hline P7 & 0.310599502 & 0.194399356 & 0.61139163 & 0.194399356 \\
\hline P8 & 0.393518519 & 0.364734014 & 0.436365617 & 0.364734014 \\
\hline P9 & 0.387923183 & 0.319430938 & 0.666923819 & 0.319430938 \\
\hline P10 & 0.608598228 & 0.251078469 & 0.559323641 & 0.251078469 \\
\hline P11 & 0.327920297 & 0.673949916 & 1.058515992 & 0.327920297 \\
\hline P12 & 0.434223722 & 0.137277969 & 0.411177839 & 0.137277969 \\
\hline P13 & 0.783228804 & 0.470844182 & 0.018518519 & 0.018518519 \\
\hline P14 & 0.609864751 & 0.233132878 & 0.545353864 & 0.233132878 \\
\hline P15 & 0.253109943 & 0.661334832 & 0.9045685 & 0.253109943 \\
\hline P16 & 0.937622878 & 0.537688361 & 0.266595927 & 0.266595927 \\
\hline P17 & 0.427658513 & 0.220493357 & 0.500342818 & 0.220493357 \\
\hline P18 & 0.039555573 & 0.449206897 & 0.794194038 & 0.039555573 \\
\hline P19 & 0.310599502 & 0.194399356 & 0.61139163 & 0.194399356 \\
\hline P20 & 0.626507099 & 0.316425217 & 0.622852965 & 0.316425217 \\
\hline P21 & 0.290930877 & 0.695081102 & 0.953299087 & 0.290930877 \\
\hline P22 & 0.728795467 & 0.435643675 & 0.240740741 & 0.240740741 \\
\hline P23 & 0.349191944 & 0.387949462 & 0.545353864 & 0.349191944 \\
\hline P24 & 0.783228804 & 0.470844182 & 0.018518519 & 0.018518519 \\
\hline P25 & 0.520437092 & 0.225286645 & 0.33384734 & 0.225286645 \\
\hline P26 & 0.793181354 & 0.620695271 & 0.266595927 & 0.266595927 \\
\hline P27 & 0.554648179 & 0.443997145 & 0.879629629 & 0.443997145 \\
\hline P28 & 0.520437092 & 0.225286645 & 0.33384734 & 0.225286645 \\
\hline P29 & 0.157203026 & 0.55745959 & 0.938479712 & 0.157203026 \\
\hline & & & & \\
\hline
\end{tabular}




\begin{tabular}{|c|c|c|c|c|}
\hline Nama & C1 & C2 & C3 & Jarak Terpendek \\
\hline P30 & 0.253109943 & 0.30200979 & 0.75381972 & 0.253109943 \\
\hline P31 & 0.514742367 & 0.43884457 & 0.414256403 & 0.414256403 \\
\hline
\end{tabular}

Proses iterasi akan terus berulang hingga posisi data sudah tidak mengalami perubahan. Hasil pengelompokkan iterasi dibandingkan dengan hasil sebelumnya dan pada perhitungan ini berhenti pada iterasi ke 6 . Hasil iterasi ke 6 ditunjukkan pada Tabel 5.

Tabel 5. Hasil perhitungan iterasi ke 6

\begin{tabular}{|c|l|c|c|c|c|}
\hline No & \multicolumn{1}{|c|}{ Nama } & C1 & C2 & C3 & $\begin{array}{c}\text { Jarak } \\
\text { Terpendek }\end{array}$ \\
\hline 1 & P1 & 0.757811841 & 0.279258835 & 0.523667609 & 0.279258835 \\
\hline 2 & P2 & 0.402655584 & 0.208434232 & 0.674196423 & 0.208434232 \\
\hline 3 & P3 & 0.763896619 & 0.266279716 & 0.5557732 & 0.266279716 \\
\hline 4 & P4 & 0.269490902 & 0.812963919 & 1.1605088 & 0.269490902 \\
\hline 5 & P5 & 0.178747708 & 0.44963152 & 0.798407965 & 0.178747708 \\
\hline 6 & P6 & 0.985725788 & 0.558048999 & 0.140072058 & 0.140072058 \\
\hline 7 & P7 & 0.458466448 & 0.164083532 & 0.569932455 & 0.164083532 \\
\hline 8 & P8 & 0.529743327 & 0.345513867 & 0.386813379 & 0.345513867 \\
\hline 9 & P9 & 0.524410429 & 0.274587602 & 0.644231825 & 0.274587602 \\
\hline 10 & P10 & 0.763896619 & 0.266279716 & 0.5557732 & 0.266279716 \\
\hline 11 & P11 & 0.278937488 & 0.61415524 & 1.019247866 & 0.278937488 \\
\hline 12 & P12 & 0.593807806 & 0.154392311 & 0.370243837 & 0.154392311 \\
\hline 13 & P13 & 0.937113068 & 0.508335408 & 0.048334571 & 0.048334571 \\
\hline 14 & P14 & 0.757811841 & 0.279258835 & 0.523667609 & 0.279258835 \\
\hline 15 & P15 & 0.18864864 & 0.611006247 & 0.851831353 & 0.18864864 \\
\hline 16 & P16 & 1.101238738 & 0.586947119 & 0.316191911 & 0.316191911 \\
\hline 17 & P17 & 0.585206473 & 0.19446504 & 0.47804467 & 0.19446504 \\
\hline 18 & P18 & 0.1632781 & 0.395495727 & 0.745636505 & 0.1632781 \\
\hline 19 & P19 & 0.458466448 & 0.164083532 & 0.569932455 & 0.164083532 \\
\hline 20 & P20 & 0.761294812 & 0.35176289 & 0.596413654 & 0.35176289 \\
\hline 21 & P21 & 0.202186336 & 0.647364093 & 0.898386407 & 0.202186336 \\
\hline 22 & P22 & 0.874817765 & 0.475869063 & 0.204554158 & 0.204554158 \\
\hline 23 & P23 & 0.465978464 & 0.369877042 & 0.488378418 & 0.369877042 \\
\hline 24 & P24 & 0.937113068 & 0.508335408 & 0.048334571 & 0.048334571 \\
\hline 25 & P25 & 0.682262772 & 0.236200144 & 0.312368894 & 0.236200144 \\
\hline 26 & P26 & 0.924977784 & 0.635083026 & 0.253501556 & 0.253501556 \\
\hline 27 & P27 & 0.659840812 & 0.416294849 & 0.863054277 & 0.416294849 \\
\hline 28 & P28 & 0.682262772 & 0.236200144 & 0.312368894 & 0.236200144 \\
\hline 29 & P29 & 0.121470062 & 0.499553925 & 0.893329328 & 0.121470062 \\
\hline 30 & P30 & 0.377797785 & 0.253978552 & 0.71507408 & 0.253978552 \\
\hline 31 & P31 & 0.63591242 & 0.441292771 & 0.355076917 & 0.355076917 \\
\hline & & & & & \\
\hline
\end{tabular}

Hasil yang peroleh pada perhitungan berhenti pada Iterasi ke 6 . dengan pusat cluster C1 : ( 0.920634921, 0.85716428, 0.785714286), C2 : ( 0.73856, 0.44118, $0.47059)$ dan C3 : ( 0.5778, 0.53571, $0.02381)$.

Kesimpulan yang dapat diambil dari perhitungan pada tabel Iterasi ke 6 Cluster ke 1 memiliki nilai titik pusat cluster centroid ( $0.920634921,0.85716428,0.785714286$ ), ada 7 pelanggan dengan kriteria Cukup. Kriteria ini terdiri dari pelanggan yang memiliki jumlah pembelian barang sedikit dan jumlah pengembalian barang banyak. Cluster ke 2 memiliki nilai titik pusat cluster centroid ( $0.73856, \quad 0.44118,0.47059$ ), ada 17 pelanggan dengan kriteria Baik. Kriteria ini terdiri dari pelanggan yang memiliki jumlah pembelian barang banyak dan pengembalian barang sedikit. Cluster ke 3 memiliki nilai titik pusat cluster centroid ( 0.5778, 0.53571, 0.02381 ), ada 7 pelanggan dengan kriteria
Sangat Baik. Kriteria ini terdiri dari pelanggan yang memiliki jumlah pembelian barang sangat banyak dan pengembalian barang paling sedikit.

\subsection{Implementasi}

Implementasi berisi paparan gambar asli dari sistem yang dikerjakan oleh penyusun dengan masalah mengelompokan pelanggan potensial dengan kategori, dan aplikasi ini nantinya akan digunakan untuk pemilik dan petugas. Hasil dari implementasi program yang telah dibangun dapat terlihat seperti pada tampilan pada gambar berikut.

Tampilan halaman beranda ditunjukkan pada Gambar 2.

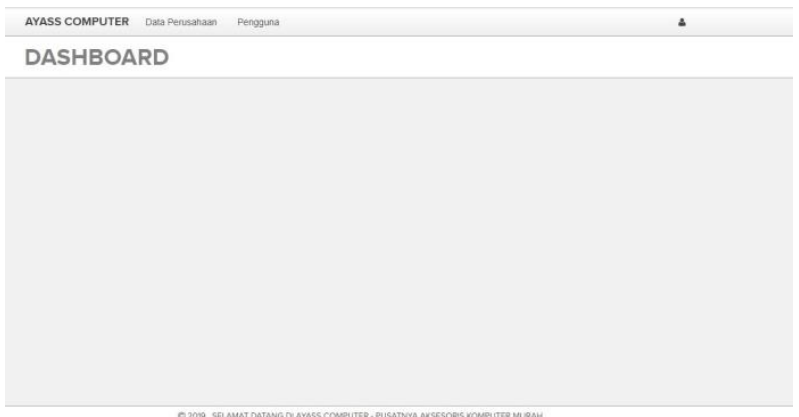

\section{Gambar 2. Halaman Beranda}

Halaman ini menampilkan hitungan iterasi dan pusat clusternya. Sistem ini berhenti pada hitungan iterasi ke 6. Tampilan halaman hitung K-Means di tunjukkan pada Gambar 3.

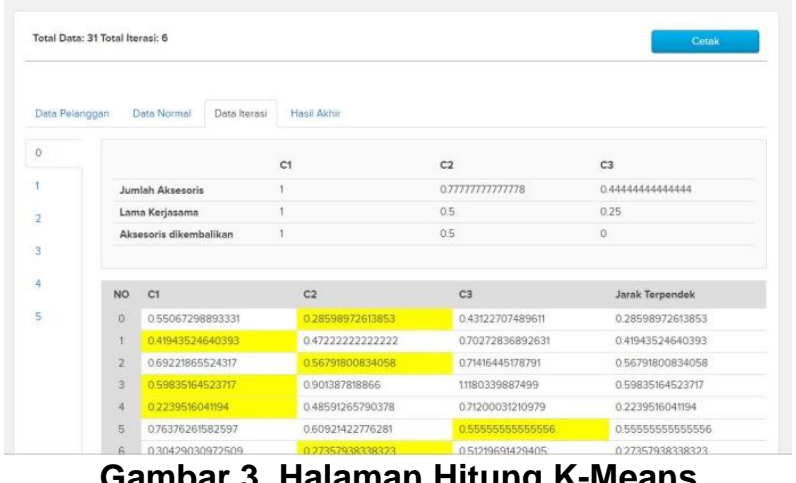

Halaman ini menampilkan data hasil akhir hitungan K-means clustering pada sistem pengelompokan pelanggan potensial di Ayass Computer. Tampilan halaman hasil akhir di tunjukkan pada Gambar 4. 


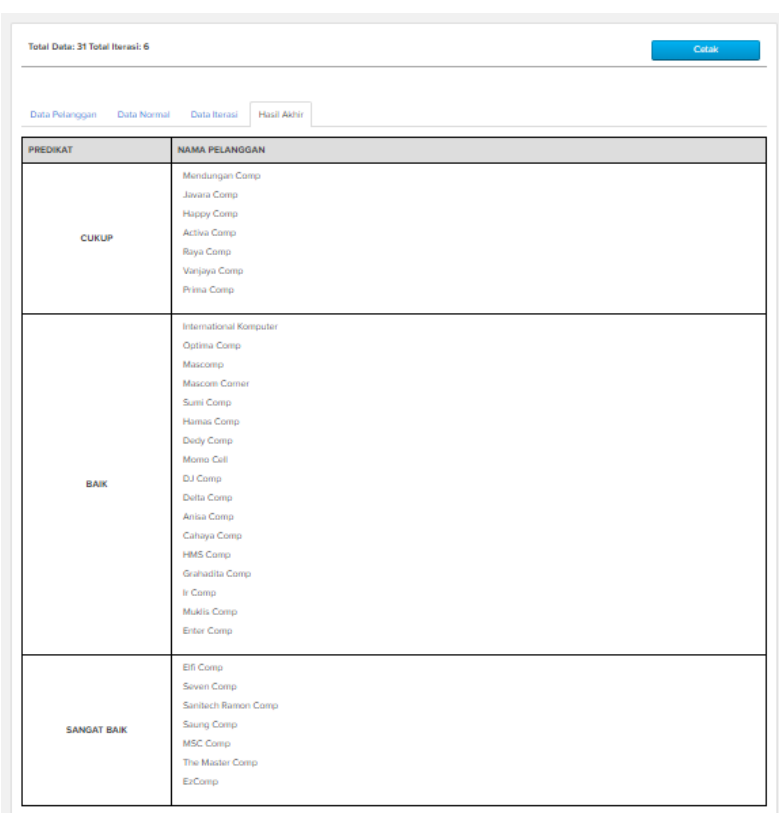

Gambar 4. Halaman Hasil Akhir

\subsection{Hasil Uji Sistem}

Sistem pengelompokan pelanggan potensial ini telah diuji secara fungsional dan perbandingan sistem hitung dengan aplikasi Microsoft excel dari pengujian di dapatkan hasil bahwa fungsi sistem sesuai dengan fungsinya dan hasil perbandingan dari aplikasi Microsoft excel sama dengan sistem yang telah dibuat. Adapun penjelasan dari fungsional sistem ditunjukkan pada Tabel 6 .

Tabel 6. Uji fungsional

\begin{tabular}{|c|c|c|c|c|}
\hline No & $\begin{array}{c}\text { Komponen } \\
\text { Sistem } \\
\text { yang diuji }\end{array}$ & Skenario Uji & $\begin{array}{c}\text { Hasil yang } \\
\text { diharapkan }\end{array}$ & $\begin{array}{c}\text { Hasil } \\
\text { Penguji }\end{array}$ \\
\hline 1 & $\begin{array}{c}\text { Login } \\
\text { Admin/User }\end{array}$ & $\begin{array}{l}\text { - Masukan } \\
\text { username dan } \\
\text { password } \\
\text { dengan benar } \\
\text { - Masukan } \\
\text { username dan } \\
\text { password } \\
\text { kosong } \\
\\
\text { - Masukan } \\
\text { username } \\
\text { dengan benar } \\
\text { dan password } \\
\text { kosong. } \\
\text { - Masukan } \\
\text { username dan } \\
\text { password } \\
\text { dengan salah }\end{array}$ & $\begin{array}{l}\text { - Tampil } \\
\text { halaman } \\
\text { utama } \\
\text { beranda } \\
\text { - Muncul } \\
\text { pesan } \\
\text { Muncul } \\
\text { pesan } \\
\text { "please fill out } \\
\text { this field" } \\
\text { pada kolom. } \\
\text { - Muncul } \\
\text { pesan } \\
\text { "please fill out } \\
\text { this field" } \\
\text { pada kolom } \\
\text { password. } \\
\text { - Muncul } \\
\text { pesan "infalid } \\
\text { credential" }\end{array}$ & $\begin{array}{l}\text { - Hasil } \\
\text { Sesuai } \\
\text { - Hasil } \\
\quad \text { Sesuai }\end{array}$ \\
\hline 2 & $\begin{array}{l}\text { Input } \\
\text { Data } \\
\text { Pelanggan }\end{array}$ & $\begin{array}{ll}\text { - } & \text { Masukan jenis } \\
\text { data } \\
\text { pelanggan. } \\
\text { - } \quad \text { Masukan data } \\
\text { aksesoris saja } \\
\text { - Masukan data } \\
\text { lama } \\
\text { kerjasama } \\
\text { saja } \\
\text { Kosongkan } \\
\text { inputan jenis } \\
\text { aksesoris dan } \\
\text { aksesoris } \\
\text { dikembalikan } \\
\end{array}$ & $\begin{array}{ll} & \text { Tampil } \\
\text { halaman } \\
\text { proses data } \\
\text { pelanggan } \\
\text { - Muncul } \\
\text { pesan } \\
\text { kesalahan } \\
\text { - Muncul } \\
\text { pesan } \\
\text { kesalahan } \\
\text { Muncul } \\
\text { pesan } \\
\text { kesalahan }\end{array}$ & $\begin{array}{ll}\text { - Hasil } \\
\text { Sesuai } \\
\text { - Hasil } \\
\text { Sesuai } \\
\text { - Hasil } \\
\text { Sesuai } \\
\text { - Hasil } \\
\text { Sesuai }\end{array}$ \\
\hline 3 & $\begin{array}{l}\text { Simpan } \\
\text { Inputan data } \\
\text { pelanggan }\end{array}$ & $\begin{array}{l}\text { - Hasil inputan } \\
\text { data } \\
\text { pelanggan }\end{array}$ & $\begin{array}{ll}- & \text { Muncul } \\
\text { pesan data } \\
\text { berhasil } \\
\text { disimpan } \\
\text { dan kembali } \\
\text { ke halaman }\end{array}$ & $\begin{array}{ll} & \text { Hasil } \\
& \text { Sesuai }\end{array}$ \\
\hline
\end{tabular}

Berdasarkan uji fungsional pada tabel 6 menunjukan sistem yang telah dibuat bebas dari kesalahan dan secara fungsional mengeluarkan hasil sesuai yang diharapkan.

\subsection{Uji Validitas}

Pengujian ini digunakan untuk membandingkan antara hasil dari sistem lama dan sistem perhitungan K-Means. Pada sistem lama sebenarnya belum ada pengelompokan pelanggan potensial yang dihitung secara rinci hanya berdasarkan nota pembelian barang saja. Sedangkan pada perhitungan K-Means atribut yang dihitung ada 3 yaitu dari pembelian barang, lama kerjsama dan barang return. Di sistem lama pun pelanggan dikelompokan ke dalam 
pelanggan potensial maupun tidak potensial, sedangkan di K-Means pelanggan dikelompokan menjadi 3 kategori yaitu kategori Cukup/Tidak Potensial, Baik/ Potensial, dan Sangat Baik/Sangat Potensial. Sistem lama dan sistem baru K-Means memiliki cara perhitungan dan kategori yang berbeda, maka dari itu untuk memudahkan membandingkannya setiap pelanggan potensial di sistem lama akan dimasukkan ke kategori Sangat Potensial. Hasil berbandingan tersebut bisa dilihat di Tabel 7.

Tabel 7. Uji Validitas

\begin{tabular}{|c|c|c|c|c|c|}
\hline $\begin{array}{l}\mathbf{N} \\
\mathbf{0}\end{array}$ & $\begin{array}{c}\text { Nama } \\
\text { Pelanggan }\end{array}$ & $\begin{array}{c}\text { Sistem } \\
\text { Lama }\end{array}$ & $\begin{array}{c}\text { Perhitung } \\
\text { an K- } \\
\text { Means }\end{array}$ & Hasil & $\begin{array}{c}\text { Presen } \\
\text { tase }\end{array}$ \\
\hline 1 & P1 & $\begin{array}{l}\text { Sangat } \\
\text { Potensial }\end{array}$ & Potensial & Relevan & $100 \%$ \\
\hline 2 & $\mathrm{P} 2$ & $\begin{array}{l}\text { Sangat } \\
\text { Potensial }\end{array}$ & Potensial & Relevan & $100 \%$ \\
\hline 3 & P3 & $\begin{array}{l}\text { Sangat } \\
\text { Potensial }\end{array}$ & Potensial & Relevan & $100 \%$ \\
\hline 4 & P4 & $\begin{array}{c}\text { Tidak } \\
\text { Potensial }\end{array}$ & $\begin{array}{c}\text { Tidak } \\
\text { Potensial }\end{array}$ & Relevan & $100 \%$ \\
\hline 5 & P5 & $\begin{array}{c}\text { Tidak } \\
\text { Potensial } \\
\end{array}$ & $\begin{array}{c}\text { Tidak } \\
\text { Potensial } \\
\end{array}$ & Relevan & $100 \%$ \\
\hline 6 & P6 & $\begin{array}{c}\text { Sangat } \\
\text { Potensial }\end{array}$ & $\begin{array}{l}\text { Sangat } \\
\text { Potensial }\end{array}$ & Relevan & $100 \%$ \\
\hline 7 & P7 & $\begin{array}{l}\text { Sangat } \\
\text { Potensial }\end{array}$ & Potensial & Relevan & $100 \%$ \\
\hline 8 & P8 & $\begin{array}{l}\text { Sangat } \\
\text { Potensial }\end{array}$ & Potensial & Relevan & $100 \%$ \\
\hline 9 & P9 & $\begin{array}{l}\text { Sangat } \\
\text { Potensial }\end{array}$ & Potensial & Relevan & $100 \%$ \\
\hline 10 & P10 & $\begin{array}{l}\text { Sangat } \\
\text { Potensial }\end{array}$ & Potensial & Relevan & $100 \%$ \\
\hline 11 & P11 & $\begin{array}{c}\text { Tidak } \\
\text { Potensial }\end{array}$ & $\begin{array}{c}\text { Tidak } \\
\text { Potensial }\end{array}$ & Relevan & $100 \%$ \\
\hline 12 & P12 & Potensial & Potensial & Relevan & $100 \%$ \\
\hline 13 & P13 & $\begin{array}{c}\text { Sangat } \\
\text { Potensial }\end{array}$ & $\begin{array}{c}\text { Sangat } \\
\text { Potensial }\end{array}$ & Relevan & $100 \%$ \\
\hline 14 & P14 & $\begin{array}{c}\text { Sangat } \\
\text { Potensial }\end{array}$ & Potensial & Relevan & $100 \%$ \\
\hline 15 & P15 & $\begin{array}{c}\text { Tidak } \\
\text { Potensial }\end{array}$ & $\begin{array}{c}\text { Tidak } \\
\text { Potensial }\end{array}$ & Relevan & $100 \%$ \\
\hline 16 & P16 & $\begin{array}{c}\text { Sangat } \\
\text { Potensial }\end{array}$ & $\begin{array}{c}\text { Sangat } \\
\text { Potensial }\end{array}$ & Relevan & $100 \%$ \\
\hline 17 & P17 & $\begin{array}{c}\text { Sangat } \\
\text { Potensial }\end{array}$ & Potensial & Relevan & $100 \%$ \\
\hline 18 & P18 & $\begin{array}{c}\text { Tidak } \\
\text { Potensial }\end{array}$ & $\begin{array}{c}\text { Tidak } \\
\text { Potensial }\end{array}$ & Relevan & $100 \%$ \\
\hline 19 & P19 & $\begin{array}{l}\text { Sangat } \\
\text { Potensial }\end{array}$ & Potensial & Relevan & $100 \%$ \\
\hline 20 & P20 & $\begin{array}{l}\text { Sangat } \\
\text { Potensial }\end{array}$ & Potensial & Relevan & $100 \%$ \\
\hline 21 & P21 & $\begin{array}{c}\text { Tidak } \\
\text { Potensial }\end{array}$ & $\begin{array}{c}\text { Tidak } \\
\text { Potensial }\end{array}$ & Relevan & $100 \%$ \\
\hline 22 & P22 & $\begin{array}{c}\text { Sangat } \\
\text { Potensial }\end{array}$ & $\begin{array}{c}\text { Sangat } \\
\text { Potensial }\end{array}$ & Relevan & $100 \%$ \\
\hline 23 & $\mathrm{P} 23$ & $\begin{array}{c}\text { Sangat } \\
\text { Potensial }\end{array}$ & Potensial & Relevan & $100 \%$ \\
\hline 24 & P24 & $\begin{array}{c}\text { Sangat } \\
\text { Potensial }\end{array}$ & $\begin{array}{c}\text { Sangat } \\
\text { Potensial }\end{array}$ & Relevan & $100 \%$ \\
\hline 25 & P25 & $\begin{array}{c}\text { Sangat } \\
\text { Potensial }\end{array}$ & Potensial & Relevan & $100 \%$ \\
\hline 26 & P26 & $\begin{array}{c}\text { Sangat } \\
\text { Potensial }\end{array}$ & $\begin{array}{l}\text { Sangat } \\
\text { Potensial }\end{array}$ & Relevan & $100 \%$ \\
\hline 27 & P27 & $\begin{array}{c}\text { Sangat } \\
\text { Potensial }\end{array}$ & Potensial & Relevan & $100 \%$ \\
\hline
\end{tabular}

\begin{tabular}{|c|l|c|c|c|c|}
\hline $\begin{array}{c}\mathbf{N} \\
\mathbf{0}\end{array}$ & $\begin{array}{c}\text { Nama } \\
\text { Pelanggan }\end{array}$ & $\begin{array}{c}\text { Sistem } \\
\text { Lama }\end{array}$ & $\begin{array}{c}\text { Perhitung } \\
\text { an K- } \\
\text { Means }\end{array}$ & Hasil & $\begin{array}{c}\text { Presen } \\
\text { tase }\end{array}$ \\
\hline 28 & P28 & Potensial & Potensial & Relevan & $100 \%$ \\
\hline 29 & P29 & $\begin{array}{c}\text { Tidak } \\
\text { Potensial }\end{array}$ & $\begin{array}{c}\text { Tidak } \\
\text { Potensial }\end{array}$ & Relevan & $100 \%$ \\
\hline 30 & P30 & $\begin{array}{c}\text { Sangat } \\
\text { Potensial }\end{array}$ & Potensial & Relevan & $100 \%$ \\
\hline 31 & P31 & $\begin{array}{c}\text { Sangat } \\
\text { Potensial }\end{array}$ & $\begin{array}{c}\text { Sangat } \\
\text { Potensial }\end{array}$ & Relevan & $100 \%$ \\
\hline
\end{tabular}

Dari hasil pengujian pada Tabel 7 dapat disimpulkan bahwa pada sistem lama mempunyai kelemahan dalam menentukan pelanggan yang benar - benar sangat potensial atau hanya sekedar potensial saja, sedangkan pada sistem k-means pengelompokan pelanggan yang potensial maupun sangat potensial di kelompokan ke kategori yang berbeda dan juga untuk perhitungan k-means menggunakan 3 atribut yang akan mendukung hasil pengelompokan lebih detail dan terinci lagi dibandingkan sistem lama.

\subsection{Uji Centroid Awal}

Pengujian ini dilakukan dengan tujuan untuk mendukung dan memastikan bahwa pengambil centroid awal secara terukur berdasarkan nilai tertinggi, medium, terendah lebih tepat untuk penelitian ini. Pengujian dilakukan dengan 10 kali percobaan dengan centroid awal yang berbeda - beda. Hasil perhitungan dapat di lihat di Tabel 8.

Dari data hasil perhitungan menggunakan pusat awal yang berbeda - beda seperti Tabel 8 dapat disimpulkan bahwa pusat awal yang berbeda akan menghasilkan data hitung akhir yang berbeda pula, namun dilihat dari hasil pengelompokan pelanggan potensial tersebut, cara pengambilan pusat awal cluster dengan cara mengambil nilai tertinggi, medium, dan terendahlah yang paling tepat dan relevan jika melihat data pelanggan dari jumlah barang yang dibeli, lama kerjasama dan barang return.

Tabel 8. Hasil Pengujian Centroid

\begin{tabular}{|c|l|l|}
\hline Percobaan & \multicolumn{1}{|c|}{ Centroid } & \multicolumn{1}{|c|}{ Hasil } \\
\hline \multirow{2}{*}{1} & $\begin{array}{l}\mathrm{C} 1=0.777777778,1,0.44444 \\
\mathrm{C} 2=0.5,1,0.25 \\
\mathrm{C} 3=0.5,1,0\end{array}$ & $\begin{array}{l}7 \text { Pelanggan di Cluster 1 } \\
17 \text { pelanggan di Cluster 2 } \\
7 \text { pelanggan di Cluster 3 }\end{array}$ \\
\hline \multirow{2}{*}{2} & $\begin{array}{c}\mathrm{C} 1=0.777777778,0.44444,1 \\
\mathrm{C} 2=0.5,0.25,1\end{array}$ & $\begin{array}{l}11 \text { Pelanggan di Cluster 1 } \\
6 \text { pelanggan di Cluster 2 } \\
14 \text { pelanggan di Cluster 3 }\end{array}$ \\
\hline \multirow{3}{*}{3} & $\mathrm{C} 3=0.5,0,0.3333$ & $\begin{array}{l}11 \text { Pelanggan di Cluster 1 } \\
\text { pelanggan di Cluster 2 } \\
14 \text { pelanggan di Cluster 3 }\end{array}$ \\
\hline
\end{tabular}




\begin{tabular}{|c|c|c|}
\hline Percobaan & Centroid & Hasil \\
\hline 4 & $\begin{array}{l}C 1=1,0.88889,0.778 \\
C 2=0.6667,0.5,0.4444 \\
C 3=0.3333,0.25,0\end{array}$ & $\begin{array}{l}7 \text { Pelanggan di Cluster } 1 \\
18 \text { pelanggan di Cluster } 2 \\
6 \text { pelanggan di Cluster } 3\end{array}$ \\
\hline 5 & $\begin{array}{l}C 1=0.8889,0.6667,0.44444 \\
C 2=0.75,0.5,0.25 \\
C 3=0.6667,0.5,0.3333\end{array}$ & $\begin{array}{l}12 \text { Pelanggan di Cluster } 1 \\
12 \text { pelanggan di Cluster } 2 \\
7 \text { pelanggan di Cluster } 3\end{array}$ \\
\hline 6 & $\begin{array}{l}C 1=1,0.6667,0.44444 \\
C 2=1,0.75,0.5 \\
C 3=1,0.5,0\end{array}$ & $\begin{array}{l}9 \text { Pelanggan di Cluster } 1 \\
7 \text { pelanggan di Cluster } 2 \\
15 \text { pelanggan di Cluster } 3\end{array}$ \\
\hline 7 & $\begin{array}{l}C 1=0.44444,0.6667,0.7778 \\
C 2=0.25,0.5,0.75 \\
C 3=1,0.5,0.6667\end{array}$ & $\begin{array}{l}14 \text { Pelanggan di Cluster } 1 \\
6 \text { pelanggan di Cluster } 2 \\
14 \text { pelanggan di Cluster } 3\end{array}$ \\
\hline 8 & $\begin{array}{l}C 1=0.44444,0.6667,0.7778 \\
C 2=0.5,0.25,0.75 \\
C 3=1,0.5,0.6667\end{array}$ & $\begin{array}{l}9 \text { Pelanggan di Cluster } 1 \\
15 \text { pelanggan di Cluster } 2 \\
7 \text { pelanggan di Cluster } 3\end{array}$ \\
\hline 9 & $\begin{array}{l}C 1=0.55556,0.66667,0.77778 \\
C 2=1,0.5,0.75 \\
C 3=0.3333,0.5,0.6667\end{array}$ & $\begin{array}{l}7 \text { Pelanggan di Cluster } 1 \\
14 \text { pelanggan di Cluster } 2 \\
10 \text { pelanggan di Cluster } 3\end{array}$ \\
\hline 10 & $\begin{array}{l}C 1=1,0.88889 .0 .77778 \\
C 2=1,0.75,0.5 \\
C 3=1,0.83333,0.66667\end{array}$ & $\begin{array}{l}7 \text { Pelanggan di Cluster } 1 \\
11 \text { pelanggan di Cluster } 2 \\
13 \text { pelanggan di Cluster } 3\end{array}$ \\
\hline
\end{tabular}

\section{PENUTUP}

\subsection{Kesimpulan}

Berdasarkan hasil penelitian yang telah dilakukan dapat diambil kesimpulan diantaranya:

1. Terciptanya perancangan dan program sistem pengelompokan pelanggan menggunakan metode K-Means Clustering, yang dapat mengelompokan pelanggan yang pantas untuk dijadikan target pemasaran atau pun target utama saat pemasaran produk baru menjadi 3 cluster yaitu cluster pertama berisi 7 data pelanggan dengan kriteria cukup. Kriteria ini terdiri dari pelanggan yang memiliki jumlah pembelian barang sedikit dan jumlah pengembalian barang banyak. cluster kedua berisi 17 data pelanggan dengan kriteria baik. Kriteria ini terdiri dari pelanggan yang memiliki jumlah pembelian barang banyak dan pengembalian barang sedikit. Cluster ketiga berisi 7 data pelanggan dengan kriteria sangat baik. Kriteria ini terdiri dari pelanggan yang memiliki jumlah pembelian barang sangat banyak dan pengembalian barang paling sedikit.

2. Hasil pengujian sudah berhasil dilakukan dalam menentukan validasi sistem. Sistem lama menggunakan 2 kategori yaitu Tidak Potensial dan Potensial, sedangkan sistem k-means menggunakan 3 kategori yaitu Tidak Potensial, Potensial, Sangat Potensial. Dengan perbedaan kategori tersebut, maka semua kategori Potensial di sistem lama akan dimasukan ke kategori Sangat Potensial dan hasilnya relevan $100 \%$.

3. Dari hasil hitung centroid awal yang berbeda-beda pada 10 kali percobaan yang sudah dilakukan, dapat diambil kesimpulan bahwa penentuan centroid awal dengan mengambil nilai tertinggi, medium, terendah lebih tepat dan relevan pada penilitian ini jika melihat data pelanggan dari jumlah barang yang dibeli, lama kerjasama dan barang return.

\subsection{Saran}

Berikut adalah saran agar penelitian berikutnya yang akan melakukan penelitian yang sama, diharapkan mendapatkan hasil yang lebih baik :

1. Pada penelitian ini pengujian sistem hanya menggunakan pengujian fungsionalitas berupa metode Black Box. Diharapkan penelitian selanjutnya menggunakan pengujian sistem yang berbeda sebagai perbandingan dalam hal pengujian kinerja sistem.

2. Untuk mengetahui tingkat kinerja sistem yang berbeda, proses pelatihan dan pengujian data untuk pengelompokan pelanggan dapat menambah variabel atau kriteria lain.

3. Dalam penentuan pusat cluster dalam penelitian ini masih menggunakan cara random. Dan diharapkan pada penelitian selanjutnya dapat menggunakan metode lain yang lebih akurat.

\section{DAFTAR PUSTAKA}

[1] H Kamber, Data Mining Concepts and Techniques. Canada, Canada: Morgan Kaufmann Publishers, 2011.

[2] Hartatik, "Pengelompokan Mahasiswa Berdasarkan Nilai Ujian Nasional Dan IPK Menggunakan Metode K-Means," Seminar Nasional Informatika, pp. Vol.1. Hal:35, 2014.

[3] Fina Nasar and Surya Darma, "Penerapan K-Means CLustering Pada Data Penerimaan Mahasiswa Baru," Seminar Nasional Teknologi Informasi dan Multimedia ( SNTIM ), pp. Vol. 2. Hal:1-73, 2015.

[4] Candra Purnamaningsih, "Pemanfaatan Metode K-Means Clustering Dalam Penentuan Penjurusan Siswa SMA," ITSMART, vol. 3, p. 27, 2014. 
[5] Istiqomah Sumadikarta and Evan Abeiza, "Penerapan Algoritma K-Means Pada Data Mining Untuk Memilih Produk Dan Pelanggan Potensial," Jurnal Satya Informatika, vol. 1, pp. 12-22, 2014.

[6] Maududie Achmad and Wibowo Wahyu, Metode Adaptive Secting Divisive Clustering Dengan Pendekatan Graf Hutan Yang Minimun. Yogyakarta: KONIK, 2014.

[7] Eni Irfiani and Siti Sulistia Rani, "Algoritma K-Means Clustering Untuk Menentukan Nilai Gizi Balita," Jurnal JUSTIN, vol. 6, p. 1, Oktober 2018.

[8] P S Roger, Rekayasa Perangkat Lunak ( Pendekatan Praktisi ). Yogyakarta, Yogyakarta: Penerbit Andi, 2012.

[9] Achmad, Maududie, and Wahyu Catur Wibowo, "Perbaikan Inisialisasi K-Means Menggunakan Graf Hutan Yang Minimum," 2014.

[10] Zulkarnain, Enterpreneurial Marketing. Yogyakarta: Graha Ilmu, 2014.

[11] Badjamal and A Faigah, "Pengaruh Kualitas Pelayanan Terhadap Kepuasan Konsumen Pada Bussines Center Sophie Paris," Jurnal Katalogis, pp. Vol. 1. Hal:122-130, 2013.

[12] Marshal B Romsey and Paul Jhon Steinbart, "Sistem Informasi Akuntansi," Jurnal Salemba Empat, p. Edisi 13, 2015.

[13] Fathansyah, "Basis Data," Jurnal ITSMART, pp. Vol. 1. Hal:100-113, 2012.

[14] Chandra Purnamaningsih, Ristu Saptono, and Abdul Aziz, "Pemanfaatan Metode KMeans Clustering Dalam Penentuan Penjurusan Siswa SMA," ITSMART, pp. Vol. 3. Hal:27, 2014.

[15] R A Asroni, "Penerapan Metode K-Means Untuk Clustering Mahasiswa Berdasarkan Nilai Akademik Dengan Weka Interface Studi Kasus Pada Jurusan Teknik Informatika UMM Magelang," SNATi, pp. Vol. 18. Hal:76-82, 2015.

[16] Lianna Felicia, "Penerapan Metode Clustering Dengan K-Means Untuk Menentukan Potensi Tanaman Padi di Kota Semarang," Fakultas IImu Komputer, pp. Vol.1. Hal:65-67, 2014.

[17] Sumadikarta and E Abieza, "Penerapan Algoritma K-Means Pada Data Mining," Satya Informatika, p. Vol. 1. No. 1, 2016. 